\title{
Heavy metal contamination risk through consumption of traditional food plants growing around Bindura town, Zimbabwe
}

\author{
P. Dzomba*, S. Nyoni and N. Mudavanhu \\ Chemistry Department, Faculty of Science Education, P Bag 1020 Bindura, Zimbabwe.
}

Accepted 16 March, 2012

\begin{abstract}
Mining activities are a leading cause of heavy metal contamination of soils and food plants leading to health risk fears. The concentration of heavy metals in soils, Bidens pilosa and Fadogia ancylantha in the vicinity of Bindura town were investigated. Results show that heavy metal concentration of soils and plants found around Bindura town was higher than that of the control area where there were no mining activities suggesting heavy metal contamination. The higher values of heavy metals may place consumers of these plants at health risk with time via bioaccumulation. It is suggested therefore that measures should be taken to lower plant and soil heavy metal accumulation.
\end{abstract}

Key words: Heavy metals, food plants, health risk, metal accumulation.

\section{INTRODUCTION}

Mining activities can contribute to heavy metal pollution of the environment (Navarro et al., 2008; Singh et al., 2005). Progressive accumulation of heavy metals in soils surrounded by mines, result in increased heavy metal uptake by food plants. This is worrisome because of potential health risk to the people leaving in the surrounding areas (Pruvot et al., 2006). Elements like Pb, $\mathrm{Cd}, \mathrm{Cr}$ and $\mathrm{Ni}$, are said to be non biodegradable thus, persist everywhere in the environment and have the ability to be deposited in various body organs which poses a great threat to the human health (Chen et al., 2005). Several researches have shown that food plants, growing in heavy metal contaminated soils have higher concentrations of heavy metals than those grown in uncontaminated soil (Akan et al., 2010). It has been reported that serious health problems may develop as a result of excessive accumulation of heavy metals such as $\mathrm{Cd}$, and $\mathrm{Pb}$ in the human body (Zhuang et al., 2008). Despite $\mathrm{Zn}$ and $\mathrm{Cu}$ being essential elements in the diet, excessive concentration in food plants is of great concern

*Corresponding author. E-mail: pdzomba@gmail.com or pdzomba@buse.ac.zw. Tel: +263773474525. Fax: +263 7536. because they are toxic to humans and animals (KabataPendias and Mukherjee, 2007). Pb and Cd metals are believed to be potential carcinogens and are implicated in the ontology of many diseases, especially cardiovascular diseases, kidney, nervous system, blood as well as bone ailments (Jarup, 2003). Recent studies reported that soil and vegetables polluted with $\mathrm{Pb}$ and $\mathrm{Cd}$ in Copsa Mica and Baia Mare, Romania, significantly contributed to decreased human life expectancy within the affected areas, reducing average age at death by 9 to 10 years (Zhuang et al., 2008). Another study reported that children living around a smelter in France (Pruvot et al., 2006) and Brazil (Bosso and Enzweiler, 2008) had high concentration of $\mathrm{Pb}$ in their blood. Türkdoğan et al. (2002) believed that the increased prevalence of upper gastrointestinal cancer rates observed in the Van region of Turkey was related to the high concentration of heavy metals in the soil, fruit and vegetables. Dietary consumption is the major route of exposure to heavy metals for most people, apart from inhalation (McBride, 2003; Khan et al., 2008). Therefore periodic monitoring of heavy metal concentrations in food plants is very important for assessing their risk to human health. Bindura town is surrounded by several mines which can be potential sources of heavy metals. Therefore, the aim 
Table 1. Certified reference material concentrations $\left(\mathrm{mg} \mathrm{kg}^{-1}\right)$.

\begin{tabular}{lcccccc}
\hline \multirow{2}{*}{ Metal } & \multicolumn{3}{c}{ CRM 1 } & \multicolumn{3}{c}{ CRM 2 } \\
\cline { 2 - 7 } & Certified value & Measured value & Recovery (\%) & Certified value & Measured value & Recovery (\%) \\
\hline $\mathrm{Cu}$ & $120 \pm 0.6$ & $119 \pm 0.5$ & 99 & $2.5 \pm 0.03$ & $2.5 \pm 0.01$ & 100 \\
$\mathrm{Zn}$ & $260 \pm 0.5$ & $258 \pm 0.4$ & 99 & $13.1 \pm 0.5$ & $12.6 \pm 0.5$ & 96 \\
$\mathrm{Cd}$ & $1.2 \pm 0.01$ & $1.1 \pm 0.05$ & 92 & $0.10 \pm 0.00$ & $0.11 \pm 0.00$ & 110 \\
$\mathrm{~Pb}$ & $73 \pm 0.5$ & $73 \pm 0.5$ & 100 & $0.11 \pm 0.01$ & $0.12 \pm 0.00$ & 109 \\
\hline
\end{tabular}

$\%$ Recovery $=$ mean measured value/mean certified value $\times 100 \%$. Values are expressed as mean $\pm S D, n=10$.

of the present study was to quantify the concentration of heavy metals in soils, Fadogia ancylantha and Bidens pilosa, herbs growing in the natural environment. $F$. ancylantha and $B$. pilosa leaves are fused to make a kind of tea believed to have medicinal properties. B. pilosa leaves are also used as relish. The two plants are highly consumed by people surrounding Bindura town.

\section{MATERIALS AND METHODS}

All reagents were of analytical grade. $\mathrm{HCL}, \mathrm{HNO}_{3}$ and $\mathrm{H}_{2} \mathrm{O}_{2}$ were obtained from Merck, New Jersey, USA. Calibration and certified reference materials were obtained from Aldrich, Steinheim, Germany. Double deionized water was used for all analysis. Analysis of heavy metal content was performed using AAS, Varian Spectra AA 600 flame Atomic Absorption spectrophotometer.

\section{Sample collection and preparation}

Plant samples were collected from grass lands around Bindura town in April, June and July 2011 and these were compared to samples collected from St Albert's in Chiweshe where there is no mining activities (control). Soil samples were collected from five points of $50 \mathrm{~m}$ apart each randomly selected. In each, soil samples were collected at a depth of 0 to $10 \mathrm{~cm}$. In all cases, samples were collected in clean polythene bags and transported straight to the laboratory. Soil samples were then dried at room temperature, crushed and passed through $2 \mathrm{~mm}$ sieve. The samples were then put in clean plastic bags and sealed. Dry plant samples (air dried at room temperature) were crushed in a mortar and the resulting powder digested by weighing $0.5 \mathrm{~g}$ of dried ground and sieved ( 1 $\mathrm{mm}$ stainless-steel mesh) into an acid-washed porcelain crucible and placed in a muffle furnace for four hours at $500{ }^{\circ} \mathrm{C}$. The crucibles were removed from the furnace and cooled. $10 \mathrm{ml}$ of $6 \mathrm{M}$ $\mathrm{HCl}$ were added covered and heated on a steam bath for $15 \mathrm{~min}$. Another $1 \mathrm{ml}$ of $\mathrm{HNO}_{3}$ was added and evaporated to dryness by continuous heating for one hour to dehydrate silica and completely digest organic compounds. Five milliliters of $6 \mathrm{M} \mathrm{HCl}$ and $10 \mathrm{ml}$ of Milli- $Q$ water were then added and the mixture heated on a steam bath to complete dissolution. The mixture was cooled and filtered through a Whatman no. 1 filter paper into $50 \mathrm{ml}$ volumetric flasks and made up to the mark with Milli-Q water. Two grammes of the soil samples were weighed into acid-washed glass beakers and digested by the addition of $20 \mathrm{~cm}^{3}$ of aqua regia (mixture of $\mathrm{HCl}$ and $\mathrm{HNO}_{3}$, ratio $3: 1$ ) and $10 \mathrm{~cm}^{3}$ of $30 \% \mathrm{H}_{2} \mathrm{O}_{2}$. The $\mathrm{H}_{2} \mathrm{O}_{2}$ was added drop wise to avoid any possible overflow leading to loss of material. The beakers were covered by means of a watch glass, and heated over a hot plate at $90^{\circ} \mathrm{C}$ for two hours. The beaker wa lls and watch glass were washed with Milli-Q water and the samples were filtered and the filtrate collected. The volumes were adjusted to $100 \mathrm{~cm}^{3}$ with Milli-Q water. Blanks were made in the same way but without samples. All samples and blanks were stored in plastic containers.

\section{Physico-chemical assay}

The $\mathrm{pH}$ was measured using a 1:2 soil: water ratio (Mclean, 1982).

\section{Elemental analysis of samples}

Determination of $\mathrm{Cu}, \mathrm{Zn}, \mathrm{Fe}, \mathrm{Cr}, \mathrm{Cd}, \mathrm{As}, \mathrm{Ni}$ and $\mathrm{Pb}$ in soil and vegetable samples were made directly on each of the final solution under atomic absorption spectroscopy (AAS).

\section{Quality assurance and quality control}

Suitable quality control and assurance protocols were carried out to ensure reliability of the results. Milli- $Q$ water was used throughout the study. Glassware was properly cleaned, and the reagents used were of analytical grade. Reagents blank determinations were used to correct the instrument readings. All analyses were performed ten times. Certified reference materials (CRM) were used for validation of the analytical procedure. The results of measurements of CRMs are summarized in Table 1.

\section{Statistical analysis}

The data was presented as mean \pm standard deviation (SD) of ten determinations. Bio-accumulation factor (BAF) values for each metal were subjected to Student's $t$ test to compare values for Bindura samples to that of control site and that of the two plant species. ANOVA was applied to compare BAF values between sites followed by multiple comparisons using the least significant difference (LSD) test. Differences were considered statistically significant at $p<0.05$. All statistical analyses were performed using SPSS 16 software (SPSS Inc., Chicago, IL, USA).

\section{Bio-accumulation factor (BAF)}

Bio-accumulation factor (BAF) is an index measuring the ability of a plant to accumulate a particular metal with respect to its concentration in the soil substrate (Ghosh and Singh, 2005). This was calculated as follows:

$\mathrm{BAF}=\mathrm{C}_{\text {plant }} / \mathrm{C}_{\text {soil }}$

where $\mathrm{C}_{\text {plant }}$ and $\mathrm{C}_{\text {soil }}$ represent the heavy metal concentration in the useful part of plants and soils, respectively. 
Table 2. Heavy metal concentration $\left(\mathrm{mg} \mathrm{kg}^{-1}\right)$ of soil collected around Bindura town.

\begin{tabular}{|c|c|c|c|c|c|c|c|c|c|}
\hline \multirow{2}{*}{ Site } & \multirow{2}{*}{$\mathrm{pH}$} & \multicolumn{8}{|c|}{ Mean total concentration } \\
\hline & & $\mathrm{Cu}$ & $\mathrm{Zn}$ & $\mathrm{Fe}$ & $\mathrm{Cr}$ & Cd & As & $\mathrm{Ni}$ & $\mathbf{P b}$ \\
\hline 1 & $5.4^{a_{*}}$ & $420^{d}$ & $254^{d}$ & $360^{c}$ & $218^{d}$ & $0.12^{a_{*}}$ & $0.52^{a_{*}}$ & $354^{d}$ & $14^{d_{*}}$ \\
\hline 2 & $5.5^{\mathrm{b} *}$ & $243^{b}$ & $256^{\mathrm{a}}$ & $380^{d_{*}}$ & $220^{\mathrm{a}}$ & $0.10^{\mathrm{a} *}$ & $0.55^{\mathrm{a} *}$ & $330^{d}$ & $16^{\mathrm{b}}$ \\
\hline 3 & $6.9^{b}$ & $331^{a}$ & $230^{d}$ & $380^{\mathrm{b} *}$ & $215^{\mathrm{a}}$ & $0.20^{\mathrm{a}}$ & $0.48^{\mathrm{b}}$ & $360^{c}$ & $13^{\mathrm{d}_{*}}$ \\
\hline 4 & $5.5^{\mathrm{a} *}$ & $345^{d}$ & $266^{d}$ & $366^{a}$ & $225^{d}$ & $0.09^{a}$ & $0.51^{\mathrm{a}}$ & $352^{c}$ & $15^{d}$ \\
\hline 5 & $6.8^{\mathrm{a}}$ & $336^{d}$ & $250^{d}$ & $350^{d}$ & $230^{d}$ & $0.11^{a *}$ & $0.56^{\mathrm{b}}$ & $365^{d}$ & $22^{b}$ \\
\hline
\end{tabular}

$\mathrm{n}=10 ; \mathrm{a}= \pm 0.00, \mathrm{~b}= \pm 0.04, \mathrm{c}= \pm 0.33$, and $\mathrm{d}=0.18$. ANOVA analysis was applied to compare results for site 1 to 5 , Student $t$ test was applied to compare results for each metal between control and Bindura town; ${ }^{*}$, = do not differ at $p=0.05$; (LSD) test.

Table 3. Heavy metal concentration $\left(\mathrm{mg} \mathrm{kg}^{-1}\right)$ of soil collected from Chiweshe (Non mining area).

\begin{tabular}{|c|c|c|c|c|c|c|c|c|c|}
\hline \multirow{2}{*}{ Site } & \multirow{2}{*}{$\mathrm{pH}$} & \multicolumn{8}{|c|}{ Mean total concentration } \\
\hline & & $\mathrm{Cu}$ & Zn & $\mathrm{Fe}$ & $\mathrm{Cr}$ & Cd & As & $\mathrm{Ni}$ & $\mathrm{Pb}$ \\
\hline 1 & $6.8^{a_{*}}$ & $200^{a}$ & $210^{a}$ & $360^{c}$ & $200^{c}$ & $0.01^{a}$ & $0.03^{a_{*}}$ & $10^{\mathrm{a}}$ & $8^{a_{*}}$ \\
\hline 2 & $6.6^{a *}$ & $210^{c}$ & $220^{d}$ & $370^{d}$ & $180^{\mathrm{C}}$ & $0.06^{\mathrm{a}}$ & $0.06^{a}$ & $15^{\mathrm{a}}$ & $10^{\mathrm{a}}$ \\
\hline 3 & $6.4^{\mathrm{b}}$ & $230^{d}$ & $211^{\mathrm{c}}$ & $378^{d}$ & $205^{d}$ & $0.02^{a_{*}}$ & $0.04^{a_{*}}$ & $20^{\mathrm{a}}$ & $6^{a}$ \\
\hline 4 & $6.8^{a_{*}}$ & $215^{\mathrm{b}}$ & $213^{\mathrm{c} *}$ & $358^{d}$ & $212^{d}$ & $0.03^{\mathrm{a}}$ & $0.04^{a_{*}}$ & $30^{b}$ & $12^{b}$ \\
\hline 5 & $6.6^{b_{*}}$ & $220^{d}$ & $214^{\mathrm{C}_{*}}$ & $330^{b}$ & $208^{d}$ & $0.02^{a_{*}}$ & $0.03^{a_{*}}$ & $28^{a}$ & $8^{a_{*}}$ \\
\hline
\end{tabular}

$\mathrm{n}=10 ; \mathrm{a}= \pm 0.00, \mathrm{~b}= \pm 0.01, \mathrm{c}= \pm 0.13$, and $\mathrm{d}=0.09$. ANOVA analysis was applied to compare results for site 1 to 5 ; Student $t$ test was applied to compare results for each metal between control and Bindura town; *, do not differ at $p=0.05$; (LSD) test.

Table 4. Heavy metal concentration $\left(\mathrm{mg} \mathrm{kg}^{-1}\right)$.of mostly consumed indigenous food/medicinal plants from Bindura town.

\begin{tabular}{ccc}
\hline \multirow{2}{*}{ Metal } & \multicolumn{2}{c}{ Plant species (Mean total concentration of metal) } \\
\cline { 2 - 3 } & F. ancylantha & B. pilosa \\
\hline $\mathrm{Cu}$ & $1.11 \pm 0.02$ & $0.60 \pm 0.01$ \\
$\mathrm{Zn}$ & $13.20 \pm 0.31$ & $25 \pm 0.05$ \\
$\mathrm{Fe}$ & $0.82 \pm 0.01$ & $0.91 \pm 0.02$ \\
$\mathrm{Cr}$ & $0.08 \pm 0.00$ & $0.09 \pm 0.00$ \\
$\mathrm{Cd}$ & $0.05 \pm 0.00$ & $0.06 \pm 0.00$ \\
$\mathrm{As}$ & $0.02 \pm 0.00$ & $0.01 \pm 0.00$ \\
$\mathrm{Ni}$ & $0.68 \pm 0.01$ & $0.88 \pm 0.01$ \\
$\mathrm{~Pb}$ & $0.95 \pm 0.04$ & $0.86 \pm 0.02$ \\
\hline
\end{tabular}

Values are expressed as mean $\pm S D, n=10$ (fresh weight basis). Student $t$ test to compare results of the two plants and results of control area and Bindura town for the same plant.

\section{RESULTS AND DISCUSSION}

The results of heavy metal contamination in plant leaves soils are shown in Tables 2 to 5 . The $\mathrm{pH}$ values of soils presented can be classified as acidic to neutral. The concentration of heavy metals in soils and plant species obtained from areas around Bindura town differs significantly to that of samples obtained from the control area $(p=0.05)$. The concentration of heavy metals in Bindura soils were highest for copper followed by iron with cadmium and arsenic being the lowest. Among the plants, the mean concentrations were highest for zinc in both plants. The mean concentrations for control soil samples were highest for iron, copper and zinc. Arsenic and cadmium were once more the lowest. The difference in mean heavy metal concentration for the control and the experimental area indicates the presence of some soil contamination.

Heavy metal contamination is more pronounced in areas around mines due to physical contamination by dust and through translocation (Itanna, 2002; Muchuweti et al., 2006). Soil to plant transfer is the major component 
Table 5. Heavy metal concentration $\left(\mathrm{mg} \mathrm{kg}^{-1}\right)$ of mostly consumed indigenous food/medicinal plants from Chiweshe (Non mining area)

\begin{tabular}{ccc}
\hline \multirow{2}{*}{ Metal } & \multicolumn{2}{c}{ Plant species (Mean total concentration of metal) } \\
\cline { 2 - 3 } & F. ancylantha & B. pilosa \\
\hline $\mathrm{Cu}$ & $0.09 \pm 0.00$ & $0.05 \pm 0.05$ \\
$\mathrm{Zn}$ & $10.12 \pm 0.05$ & $16.10 \pm 0.03$ \\
$\mathrm{Fe}$ & $0.08 \pm 0.00$ & $0.06 \pm 0.00$ \\
$\mathrm{Cr}$ & $0.02 \pm 0.00$ & $0.02 \pm 0.00$ \\
$\mathrm{Cd}$ & $0.00 \pm 0.00$ & $0.01 \pm 0.00$ \\
$\mathrm{As}$ & $0.00 \pm 0.00$ & $0.00 \pm 0.00$ \\
$\mathrm{Ni}$ & $0.01 \pm 0.00$ & $0.00 \pm 0.00$ \\
$\mathrm{~Pb}$ & $0.01 \pm 0.04$ & $0.00 \pm 0.00$ \\
\hline
\end{tabular}

Values are expressed as mean $\pm S D, n=10$ (fresh weight basis); Student $t$ test to compare results of the two plants and results of control area and Bindura town for the same plant.

of human exposure to heavy metals through the food chain. The present results show that BAF values e. g. for zinc $0.00264-0.005045$ differed significantly for the five chosen areas (ANOVA, $p=0.05$ ). The difference can be rationalized by the fact that soil nutrient management differs due to soil properties Liu et al. (2005). Comparing the two studied species, BAF values for the metals $\mathrm{Cu}-$ $\mathrm{Pb}$ differed significantly. The result of the present study was compared with previous studies (Khan et al 2008; Cui et al., 2004). BAF values obtained in these studies differed significantly. For a given metal, the transfer value varies greatly with plant species (Cui et al., 2004).

\section{Conclusions}

The present study reveals that soil samples collected from areas around Bindura town consist of higher heavy metal concentration which might cause health risk to the local inhabitants through contamination of indigenous and medicinal plants. The present studied plants show higher heavy metal content as compared to control samples. It is therefore recommended that measures should be taken to arrest heavy metal contamination risk.

\section{ACKNOWLEDGEMENT}

The researchers would like to thank Bindura Research Center and Kutsaga Research Unit for their kind help.

\section{REFERENCES}

Akan JC, Abdulrahaman FI, Sodipo OA, Lange AG (2010). Physicochemical parameters in soil and vegetable samples from Gongulon Agricultural site, Maiduguri, Borno state, Nigeria. J. Am. Sci., 6: 12.

Bosso ST, Enzweller J (2008). Bioaccessible lead in soils, slag and mine waste from abandoned mining district in Brazil. Environ. Geochem. Health, 30: 219-229.
Chen Y, Wang C, Wang Z (2005). Residues and source identification of persistent organic pollutants in farmland soils irrigated by effluents from biological treatment plants. Environ. Intern., 31: 777-783.

Cui YJ, Zhu YG, Zhai RH, Chen DY, Huang ZH, Qiu Y (2004). Transfer of metals from soil to vegetables in an area near a smelter in Nanning, China. Environ. Int., 30: 785-91.

Itanna F (2002). Metals in leafy vegetables grown in Addis Ababa and toxicological implications. Ethiop. J. Health Dev., 6: 295-302.

Jarup L (2003). Hazards of heavy metal contamination. Brit. Med. Bull., 68: 167-182.

Kabata-Pendias A, Mukherjee AB (2007). Trace elements from soil to human. NewYork: Springer-Verlag.

Khan S, Cao Q, Zheng YM, Huang YZ, Zhu YG (2008). Health risks of heavy metals in contaminated soils and food crops irrigated with waste water in Beijing, China. Environ. Pollut., 152: 686-692.

Liu HY, Probst A, Liao BH (2005). Metal contamination of soils and crops affected by the Chenzhou lead zinc mine spill (Hunan, China). Sci. Total Environ., 339: 153-166.

McBride MB (2003). Toxic metals in sewage sludge-amended soils: has promotion of beneficial use discounted the risks? Adv. Environ. Res., (8): 5-19.

Mclean EO (1982). Soil pH and lime requirement. In: A.L. Page, R.H. Miller, and D.R. Keeney (eds.), Methods of Soil Analysis. Part 2: Chemical and Microbiological Properties. 2nd ed. American Society of Agronomy. Madison. WI, pp. 199-224.

Muchuweti M, Birkett JW, Chinyanga E, Zvauya R (2006). Scrimshaw MD, Lester JN. Heavy metal content of vegetables irrigated with mixtures of wastewater and sewage sludge in Zimbabwe: implications for human health. Agric. Ecosyst. Environ., 112: 41-48.

Navarro MC, Perez-Sirvent C, Martinez-Sanchez MJ, Vidal J, Tovar PJ, Bech J (2008). Abandoned mine sites as a source of contamination by heavy metals: A case study in a semi-arid zone. J. Geochem. Explor., 96: 183-193.

Pruvot C, Douay F, Herve F, Waterlot C (2006). Heavy metals in soil, crops and grass as a source of human exposure in the former mining areas. J Soils Sediments, 6: 215-220.

Singh AN, Zeng DH, Chen FS (2005). Heavy metal concentrations in redeveloping soil of mine spoil under plantations of certain native woody species in dry tropical environment, India. J Environ. Sci., 1: $168-174$

Türkdoğan MK, Kilicel F, Kara K, Tuncer I, Uygan I (2002). Heavy metals in soil, vegetables and fruits in the endemic upper gastrointestinal cancer region of Turkey. Environ. Toxicol. Pharmacol., 13: 175-179.

Zhuang P, McBride MB, Xia H, Li H, Li Z (2008). Heavy metal contamination in soils and food crops around Dabaoshan mine in Guangdong, China: implication for human health. Environ. Geochem. Health, 31: 707-715. 